\title{
An Effect of Oregano on Oxidative Stability of Soybean Oil Via Microwave and Induction Cook Top Heating
}

\section{Geeta Verma*}

Department of Chemistry, Chandra Shekhar Azad Government Post Graduate Nodal College, Sehore, Madhya Pradesh, India

\begin{abstract}
The main objective of this study is to evaluate the antioxidant properties of oregano on refined soybean oil as a result of microwave and induction cook top heating. Oxidation changes were determined by common traditional parameters such as acid value, free fatty acid value, peroxide value as well as by Fourier transform infrared (FTIR) spectroscopy. It has been observed from studies that oregano has powerful antioxidant effect in microwave heated oil samples whereas it does not show any antioxidant properties on induction cooktop heated samples.
\end{abstract}

Keywords: Fourier transform infrared spectroscopy; Peroxide value; Free fatty acid; Microwave induction cook top

\section{Introduction}

Oil and fats are important parts of the healthy human diet as they are also used as food preparation and flavoring. Edible oils are vital constituents of our daily diet, which provide energy, essential fatty acids and serve as a carrier of fat soluble vitamins [1-3]. Fats and oil belongs to a group of biological substances called lipids. Lipids and triacylglycerol naturally occur in oils and fats. Their chemical composition contains saturated and unsaturated fatty acids and glycerides. India is sixth largest producer of Soy oil in the world (Figures 1-3). Soybean oil is $61 \%$ polysaturated fatty acid (PUFA) and $24 \%$ monounsaturated fatty acid (MUFA) which is comparable to the total unsaturated fat content of other vegetable oil $(\sim 85 \%)$. Literature survey shows possible effect of oregano in corn oil via thermal and ultraviolet exposure to oil, no research paper is available related to antioxidant effect of oregano on edible oil via microwave and induction cooktop heating. So it was decided to carry out research via both microwave and induction cooktop heating.

\section{Materials and Methods}

Both Samples of refined oil $(50 \mathrm{ml})$ with and without oregano were placed in stainless steel pan having diameter of $20 \mathrm{~cm}$ at $240^{\circ} \mathrm{C}$ (at 1600 $\mathrm{W}$ ) on induction cooktop heating. Similarly oils samples $(50 \mathrm{ml})$ were heated with and without oregano in microwave oven LG for 30 minutes in a petridishes $(8 \mathrm{~cm}$ diameter $)$ temperature during after $30 \mathrm{~min}$ heating reached to $186^{\circ} \mathrm{C}$. In this experiments oregano was added to oil concentration used was $0.05 \% \mathrm{w} / \mathrm{w}$ [4-6]. Oil samples were cooled for the analysis and kept in glass vial till the analysis. All the reagents were AR grade and acid value peroxide value determination were performed by use of $10 \mathrm{ml}$ burette (grade 'A' with graduation intervals of $0.05 \mathrm{ml}$ ) as the graduation level of the commonly used burette ( $50 \mathrm{ml}$ capacity) was found to insufficient to capture the reading accurately or precisely (Figures 4 and 5).

\section{Oils}

Refined soybean oil of fortune brand of Adani wilmer company and Oregano were purchased from local market.

\section{Determination of Free Fatty Acid (FFA) and acid value}

The acid value and FFA content was determined by directly titrating the heated oil samples in an alcoholic medium against standard Potassium hydroxide solution (Figures 6 and 7).

$$
\text { Acid value }=\frac{56.1 \times N V}{W}
$$

where, $\mathrm{AV}=1.99 \times \mathrm{FFA} ; \mathrm{V}=$ Volume in $\mathrm{ml}$ standard $\mathrm{KOH}$; $\mathrm{N}=$ Normality of $\mathrm{KOH}$ solution; $\mathrm{W}=\mathrm{W}$ eight in gm of the oil; FFA conc. in the heated oils is calculated as percent oleic acid.

\section{Determination of peroxide value}

Peroxide value determination was done according to AOCS standard methods. The values were expressed as meq of peroxide $\mathrm{O}_{2} /$ $\mathrm{Kg}$ oil and $\mathrm{mg} \mathrm{KOH} / \mathrm{gm}$ oil respectively [7-10].

$$
\text { Peroxide Value }=\frac{10 \times V}{W}
$$

where, $\mathrm{V}=$ Volume of $0.01 \mathrm{~N} \mathrm{Na}_{2} \mathrm{~S}_{2} \mathrm{O}_{3}$ solution; W=Weight in gm of the oil; "MWO (Microwave heated oil with oregano), MWWO (Microwave heated oil without oregano), IHO (Induction heated oil with oregano), IHWO (Induction heated oil without oregano).

\section{Results and Discussion}

Gullien and Cabo developed respective methods which is based on Fourier transform infrared spectroscopy FTIR and assumes that frequency changes in specific band allow the differentiation of stages of the oxidation process and detection of the oxidation level of the heated oil sample. FTIR spectra of soybean oils heated with and without oregano on microwave and induction heated oils sample shows different intensities on different wave length. The result obtained by measuring the intensity of FTIR absorption at different frequency for heated refined soybean oils via two different methods of heating are presented in Table 1. It is clear from data that sample heated with oregano in microwave prevents oxidation of oil accelerated by high temperature while in case of Induction heating it had not happened as percentage transmittance of oil heated with oregano increases and absorbance decreases. Same results are obtained by titration methods where free fatty acid and peroxide formation was more in sample which was heated without oregano and less in sample heated with oregano in a microwave heating. Surprisingly, it was observed by data that sample heated in induction with oregano shows reverse result as compare

*Corresponding author: Verma G, Chandra Shekhar Azad Government Post Graduate Nodal College, Sehore, Madhya Pradesh, India, Tel: +918839192534 E-mail: drgitaverma@yahoo.co.in

Received August 24, 2017; Accepted September 04, 2017; Published September 08, 2017

Citation: Verma G (2017) An Effect of Oregano on Oxidative Stability of Soybean Oil Via Microwave and Induction Cook Top Heating. Mod Chem Appl 5: 231. doi: 10.4172/2329-6798.1000231

Copyright: @ 2017 Verma G . This is an open-access article distributed under the terms of the Creative Commons Attribution License, which permits unrestricted use, distribution, and reproduction in any medium, provided the original author and source are credited. 


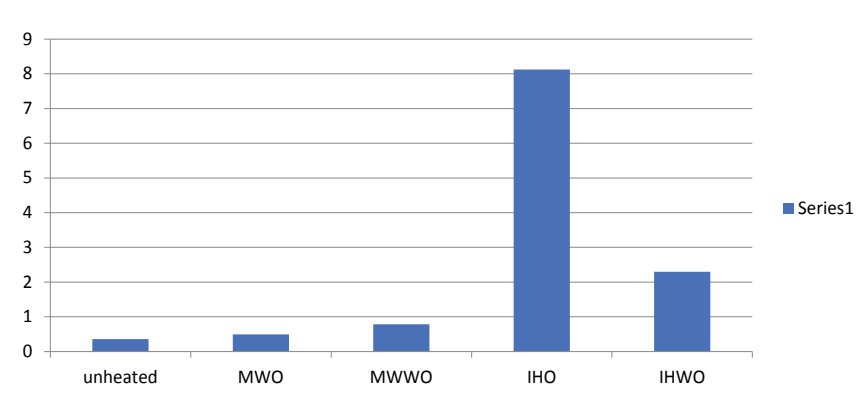

Figure 1: Acid value of microwave and induction heated oils sample (with or without oregano).

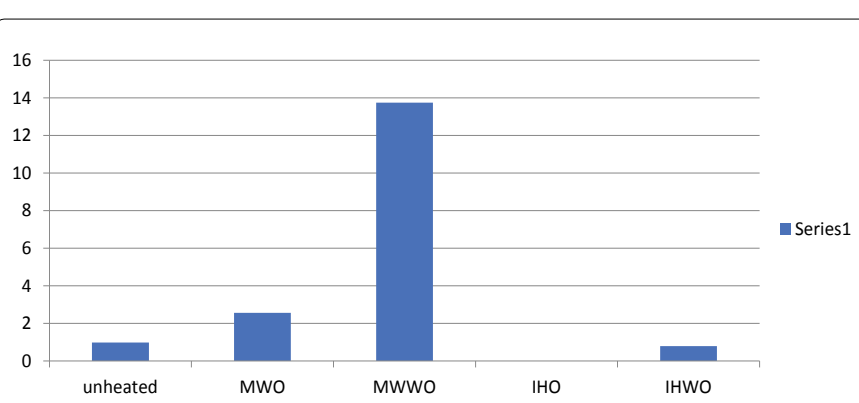

Figure 2: Peroxide value of microwave and induction heated oils sample (with or without oregano).

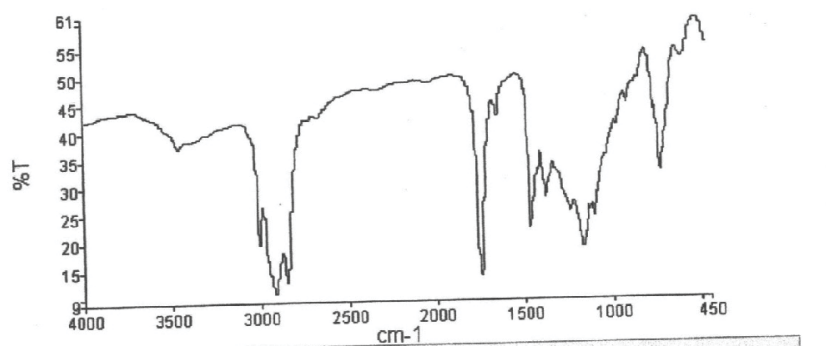

Figure 3: IR spectra of unheated soybean oil.

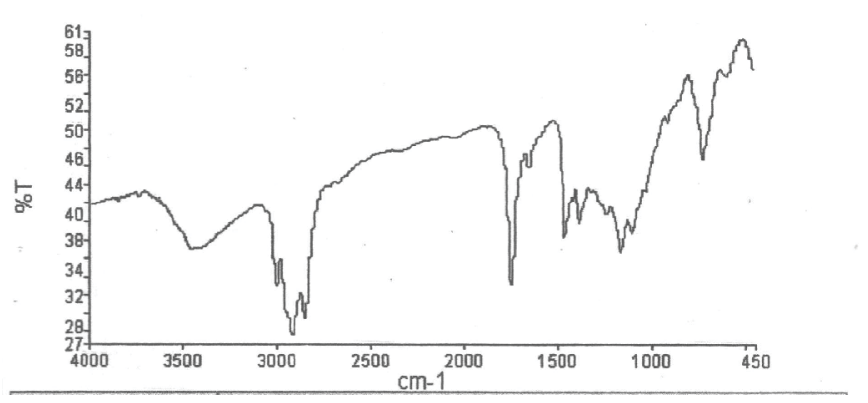

Figure 4: IR spectra of soybean oil MWO.

\begin{tabular}{|c|c|c|c|c|c|c|}
\hline Wave No. cm $^{-1}$ & 3670 & 3009 & 2925 & 2854 & 1745 & 1654 \\
\hline Unheated & - & 0.71 & 0.9 & 0.98 & 0.88 & 0.37 \\
\hline MWO & - & 0.48 & 0.56 & 0.53 & 0.48 & 0.34 \\
\hline MWWO & 0.37 & 0.66 & 0.79 & 0.75 & 0.7 & 0.38 \\
\hline IHO & 0.43 & 0.49 & 0.59 & 0.56 & 0.5 & - \\
\hline IHWO & - & 0.51 & 0.63 & 0.59 & 0.59 & - \\
\hline
\end{tabular}

Table 1: FTIR Absorption for nonheated and heated Soybean oil samples.
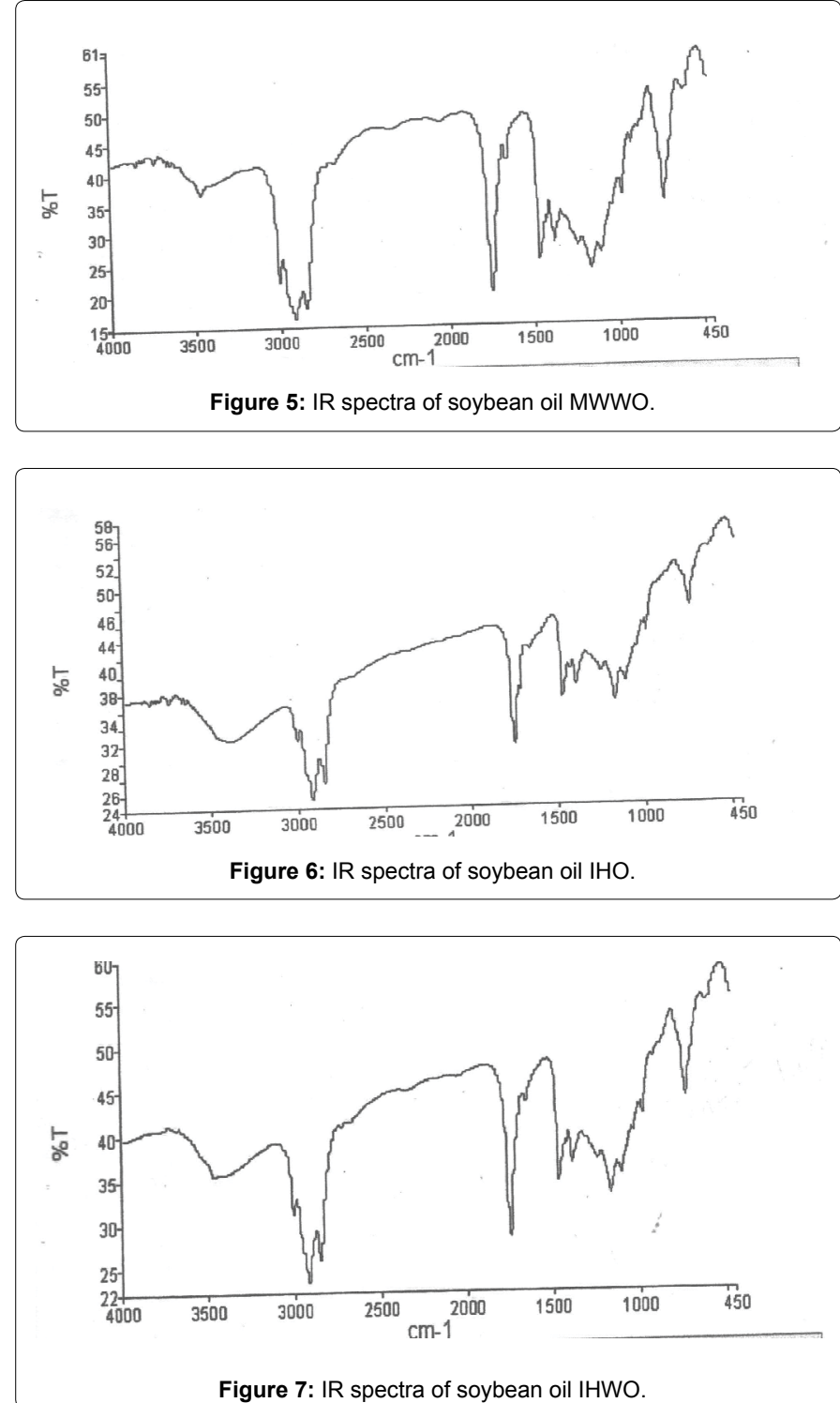

to microwave sample that may be due to very fast heating of oil thus destroying antioxidant properties of oregano. One additional peak at $3670 \mathrm{~cm}^{-1}$ corresponding to secondary oxidized product are observed in case of microwave heated sample without oregano and induction heated sample with oregano which indicates the starting of formation of free fatty acids due to primary oxidation products degradation. The primary oxidation products at high temperature rapidly decomposed to aldehydes, ketones, acids, esters, alcohols and short chain hydrocarbon.

\section{Conclusion}

In this study soybean oil heated with or without oregano via microwave and induction cook top devices and some of its physiochemical parameters were determined by both conventional and spectroscopic methods. During induction cook top treatment in sample that was treated with oregano it can be observed that oil undergoes oxidative degradations and increase in free fatty acid value, while in microwave heated sample with oregano very well shows its antioxidant properties by preventing oxidation and results are found in good correlation with FTIR spectroscopic data. Main outcome of research suggests antioxidant like oregano can be used to prevent 
oxidative degradation via microwave heating. In future study on other oils at different temperature via microwave can be carried out to evaluate the possible antioxidant properties of Oregano.

\section{Acknowledgements}

The author wishes to acknowledge Dr. Brijesh Kumar, Head, SAIF and their staff, CSIR Central Drug Research Institute, Lucknow for providing FTIR spectroscopic data. Author also wishes to thanks her family for their support during investigation.

\section{References}

1. Diana M, Mariana P, loan G (2012) Quality characteristic and oxidative stability of coconut oil during storage. Journal of Agroalimentary Processes and Technologies 180: 272-276

2. Gullien MD, Calo N (2002) Fourier transform infrared, spectra versus peroxide and anisidine value to determine oxidative stability of edible oils. Food Chemistry 77: 503-510.

3. Rohman A, Che MYB, Sismindari S (2009) Quantitative analysis of virgin coconut oil ( $\mathrm{VCO}$ ) in cream cosmetics preparations using Fourier transform infrared, spectroscopy. Pakistan Journal of Pharmaceutical Sciences 22: 415-420.
4. Ojeh O (1981) Effects of refining on the physical and chemical properties of cashew kernel oil. J Fats Oils Technol 16: 513-517.

5. Alexa E, Dragomirescu A, Pop G (2009) The use of FTIR spectroscopy in the identification of vegetable oils adulteration. Journal of Food Agriculture and Environment 7: 20-24.

6. Rohman A, Cheman YB, Ismail A (2011) Monitoring the oxidative stability of virgin coconut oil during oven test using chemical indexes and FTIR spectroscopy. International Food Research Journal 18: 303-310.

7. Vlachos $Y$, Skopelitis M, Psaroudaki V (2006) Application of Fourier transform infrared, spectroscopy to edible oils. Analytica Chimica Acta 573: 459-465.

8. Erum Z, Rehana S, Mehwish AH, Anjum Y (2014) Study of physiochemical properties of edible oil and evaluation of frying oil quality by Fourier transform (FT-IR) infrared spectroscopy.

9. Siong FS, Ferri Z, Ean L (2014) Synchronized Analysis of FTIR spectra and GCMS chromatograms for Evaluation of the Thermally Degraded Vegetable Oils. Journal of Analytical Methods in Chemistry 2014: 1-9.

10. Lukesova D, Dostalova J, Moneim M, Svarovska M (2009) Oxidative changes of Vegetables Oils during Microwave Heating. Czech J Food Science 23: 230239 